\title{
Cognitive function of idiopathic childhood epilepsy
}

Su Jeong You, MD, PhD

Department of Pediatrics, Epilepsy Center, Sanggye Paik Hospital, Inje University College of Medicine, Seoul, Korea

Received: 10 February 2012, Accepted: 26 February 2012 Corresponding author: Su Jeong You, MD, PhD

Department of Pediatrics, Epilepsy Center, Sanggye Paik Hospital, Inje University College of Medicine, 1342 Dongilro, Nowon-gu, Seoul 139-707, Korea

Tel: +82-2-950-1080, Fax: +82-2-951-1246

E-mail: sjyou@paik.ac.kr
Most children with epilepsy are of normal intelligence. However, a significant subset will have temporary or permanent cognitive impairment. Factors that affect cognitive function are myriad and include the underlying neuropathology of the epilepsy, seizures, epileptiform discharges, psychosocial problems, age at seizure onset, duration of epilepsy, and side effects associated with antiepileptic drugs. This review article discusses cognitive function in children with idiopathic epilepsy and the effects of antiepileptic drugs on cognitive function in children.

Key words: Epilepsy, Child, IQ, Idiopathy, Cognition, Seizures

Copyright (C 2012 by The Korean Pediatric Society

This is an open-access article distributed under the terms of the Creative Commons Attribution Non-Commercial License (http://creativecommons.org/licenses/by$\mathrm{nc} / 3.0 /$ ) which permits unrestricted non-commercial use, distribution, and reproduction in any medium, provided the original work is properly cited.

\section{Introduction}

It is now generally acknowledged that a subset of people with epilepsy will manifest some degree of cognitive impairment; moreover, an association between childhood epilepsy and cognitive dysfunction has long been recognized. Cognitive impairments have been attributed to interactions among genetics, ongoing seizures, different epilepsy syndromes, subclinical epileptiform discharges, psychosocial issues, underlying causes of symptomatic epilepsy, and treatment with antiepileptic drugs (AEDs) ${ }^{1,2}$. All of these factors are interrelated, and their contributions to cognitive deficits are complex. Predictors of cognitive decline in these patients include overmedication, poor seizure control, and young age at onset of epilepsy ${ }^{3)}$. As a group, children with symptomatic epilepsy are at a greater risk for cognitive impairment than are those with idiopathic epilepsy $y^{3)}$. Thus, studies of patients with idiopathic epilepsies may be useful in understanding whether cognitive impairment is related to stable, disease-related characteristics of the epilepsy or to paroxysmal epileptic activity, including the acute effects of seizures and the effects of interictal epileptiform discharges as observed on electroencephalogram (EEG) $)^{4)}$.

This review discusses the effects of idiopathic epilepsy, excluding epileptic encephalopathy, that are associated with cognitive decline or arrest, and the effects of AEDs, which are potentially modifiable, on cognitive function in children.

\section{Epileptic syndrome}

Some degree of cognitive dysfunction has been observed in children with idiopathic generalized epilepsy (IGE) and partial epilepsy ${ }^{5-7)}$. This review will discuss cognitive function related to several idiopathic epileptic syndromes in childhood, including those classified as IGEs and idiopathic focal epilepsies, excluding epileptic encephalopathies.

\section{IGES}

The IGEs are regarded as benign and easily controlled disorders. The cognitive function of patients with IGE is usually within the normal range, but tends to be somewhat lower than in the general population $^{8-10)}$. Moreover, despite having normal intelligence, 
children with IGE show reduced memory performance and slowed psychomotor response ${ }^{10}$. When matched for intelligent quotient (IQ), individuals with IGE showed poorer performances on tests of visual sustained attention and had greater difficulty with more complex tests than epileptic individuals with frontal or temporal foci ${ }^{11)}$. In addition, a group of children with IGE performed more poorly than controls on tasks of visual memory, whereas the 2 groups performed equally well on tasks of verbal memory ${ }^{12}$.

\section{1) Juvenile myoclonic epilepsy (JME)}

Cognitive correlates of JME have received little attention despite the extensive literature on cognition in other types of epilepsy. Neuropsychological studies have shown that subjects with JME are impaired in several frontal functions, including mental flexibility, concept formation, cognitive speed, working memory, verbal fluency, perseveration, and planning ${ }^{13,14)}$. Assessments of frontal lobe function in 15 adults with histories of JME and normal IQ showed that nearly half were impaired on 4 or more of 11 tests of frontal lobe function, although the impact of interictal EEG discharges was unclear $^{15)}$. Impairments in verbal and executive functioning may have important ramifications for the social, occupational, and academic performance of individuals with $\mathrm{JME}^{16}$. Cognitive performance may be independent of EEG activity. Significant executive dysfunction in children with JME has been associated with significantly smaller thalami and increased frontal cerebrospinal fluid ${ }^{17)}$. Children with recent-onset benign childhood epilepsy with centrotemporal spikes (BCECTS), did not display the same pattern. Thus, frontal and thalamic volumes appear to mediate the relationship between executive functioning and brain structure in individuals with JME.

A study comparing the neuropsychological performances of 50 patients with JME with 50 age-, education-, and gender-matched controls found that the former group showed more extensive deficits than observed in other studies ${ }^{8}$. For example, the JME group showed significantly poorer performance in tests of attention, inhibition, working memory, processing speed, and mental flexibility, in addition to deficits in verbal and visual memory, naming, and verbal fluency.

\section{2) Childhood absence epilepsy (CAE)}

Patients with CAE showed slight but statistically significant deficits in global cognitive function, visual spatial function, and visual memory, although their verbal skills and verbal memory were less affected ${ }^{18)}$. Compared with control individuals, patients with CAE have demonstrated higher rates of impaired behavior, emotion, cognition, and language, and lower intervention rates. These impairments particularly affected CAE patients with longer duration of illness, those with controlled seizures, and those treated with AEDs ${ }^{9}$.

\section{Idiopathic partial/focal epilepsy}

\section{1) BCECTS (benign rolandic epilepsy)}

BCECTS is the most common form of epilepsy in childhood, and several clinical studies have assessed the prevalence of cognitive impairments and learning disabilities in these children. Although most children with BCECTS display normal cognitive function and have a very good prognosis with regard to their seizures, several neuropsychological problems have been identified in individuals with active epilepsy and epileptiform discharges.

Because of the topography of discharges in patients with BCECTS, there is considerable interest in assessing language function in these individuals ${ }^{19-22)}$. Deficits in reading, writing, morphosyntax, auditoryverbal learning, and auditory discrimination ${ }^{20)}$ have been reported in children with BCECTS, along with impairments in short-term memory $^{21,22)}$, executive function ${ }^{21,22)}$, visual and perceptive abilities ${ }^{22)}$, and fine motor activity ${ }^{23)}$. Interictal activity was found to cause the laterality of speech perception to be reorganized, resulting in a bilateral representation of auditory and verbal stimuli and a loss of the usual right ear/left hemisphere advantage in processing these stimuli ${ }^{24)}$. A higher spike frequency on EEG was found to correlate with poorer outcomes in visual perception, fine motor performance, shortterm memory, and behavioral status, suggesting that focal epileptic activity may alter the cerebral mechanisms underlying cognitive functioning ${ }^{19)}$. The correlation between epileptic events, such as seizures or sharp-wave discharges, and cognitive impairment ${ }^{19)}$, along with findings of transitory cognitive impairment concomitant with sharp-wave discharge on EEG recordings ${ }^{25)}$, strongly indicates that epilepsy has direct effects on cognitive capacities.

However, there have been studies that have assessed children and found no correlation between EEG patterns and cognitive abilities ${ }^{726}$. Although EEG features were minimally associated with cognitive variables, there was no relationship between spike burden and laterality ${ }^{25}$. Improvements in verbal memory and receptive language, but not in visual memory performance and phonological awareness, were observed ${ }^{27}$. Epileptiform discharges on EEG in the absence of seizures did not appear to have an independent effect on cognitive function $^{28)}$.

To determine whether the cognitive deficits are transient or chronic, several studies have investigated the long-term cognitive outcomes in patients with BCECTS. For example, a study that followed 22 children with BCECTS from the onset of seizures until remission found an inverse relationship between performance on various subtests of the Wechsler Intelligence Scale for Children 
and the density of the paroxysmal EEG abnormalities ${ }^{29)}$. After 18 months, children with greater EEG anomalies and a persistent focus scored significantly lower on tasks involving working memory, verbal comprehension, attention, and sequential operations. A 2-year followup study showed improvements in visual-motor coordination, shortterm non-verbal memory, attention, and flexibility ${ }^{22)}$, and normal attentional abilities and visual-motor performance were observed in a cohort of children with BCECTS who had been in remission for 4 years ${ }^{30}$. Another prospective study following 19 children with BCECTS and 3 with paroxysmal occipital epilepsy for up to 3 years found that 8 of the children with BCECTS were slow learners and required special education, with 4 of these showing delayed language development ${ }^{26)}$. Eight other children had low scores in specific learning areas, which subsequently improved or became normal with normalization of their EEGs. Improved or normal performance was seen more frequently in patients with complete remission (no seizures or EEG abnormalities). Since there have been few follow-up studies in adults, there is as yet no general consensus as to whether these deficits are transient or chronic.

Although the term "benign" refers to the spontaneous disappearance of seizures or their complete control with AEDs, without relapse after cessation of treatment, care should be taken in describing epilepsy as benign in respect to the cognitive development of children with BCECTS.

\section{2) Childhood epilepsy with occipital paroxysms}

Although there have been few studies on this syndrome, several neuropsychological investigations have found cognitive impairments in children with benign epilepsy with occipital paroxysms (BEOP) $)^{31-}$ ${ }^{33)}$. In one study, children with BEOP demonstrated significantly lower performance than controls matched for age, sex, and socioeconomic status on measures of intellectual functioning, particularly on performance $\mathrm{IQ}^{31}$. Another study, however, found no betweengroup differences in performance IQ, although verbal IQ was lower in children with BEOP than in controls ${ }^{32}$. In both studies, the children with epilepsy showed significantly reduced performance across a wide variety of cognitive tasks, including attention, memory, visuospatial skills, language skills, and motor skills. Although another study found that between-group differences remained significant when controlling for intellectual functioning, there were no betweengroup differences in academic achievement, visuomotor skills, or executive functioning ${ }^{33)}$. Thus, to date, there is no consensus about the relationship between cognitive function and BEOP, which suggests the need for further prospective studies.

\section{Idiopathic generalized vs. idliopathic focal epilepsy}

Few studies have directly compared cognition in children with idiopathic or cryptogenic generalized and partial epilepsy ${ }^{2,34)}$. Compared with children with generalized epilepsy, those with BCECTS scored significantly better on performance, but not on verbal and full-scale, IQ tests $^{34)}$, suggesting that children with BCECTS may have slightly lower verbal IQs than normal controls, but similar verbal deficiencies to children with IGE. Patients with generalized seizures had lower vocabulary scores than patients with focal seizures ${ }^{2}$. The impairment index, however, was significantly higher in children with new-onset epilepsy (9.3\%) than in controls (1.5\%), with no difference between children with focal (8.7\%) and primary generalized (10.0\%) epilepsy ${ }^{35}$.

\section{Antiepileptic drugs}

Most AEDs have the potential to exert detrimental effects on cognitive function, although some may also improve cognitive performance. These beneficial influences may be due to seizure control, or they may be associated with positive effects on mood and/ or psychiatric profile. Several AEDs may enhance cognitive function more directly, by improving alertness or cognitive capacity. A thorough appreciation of the cognitive effects associated with AEDs may enhance their therapeutic success.

An older agent likely to have the greatest negative effect on cognition is phenobarbital. Studies involving children with epilepsy have linked phenobarbital to lower $\mathrm{IQ}^{36}$, and discontinuation of the drug can improve total IQ (mainly affecting nonverbal items) in children ${ }^{37)}$.

Several cognitive and psychomotor effects have also been linked to carbamazepine. A double-blind trial reported that this agent was associated with deterioration in measures of information processing speed and attention ${ }^{38)}$. However, carbamazepine may also have positive effects on cognition, consisting mainly of improvements in memory ${ }^{39)}$.

Among the other older AEDs, the cognitive effects associated with phenytoin may be more obvious but are generally restricted to visually guided motor functions ${ }^{38)}$. Several studies have indicated that valproate has little detrimental impact on cognitive function ${ }^{40,411}$, although minor changes have been reported in children ${ }^{42}$. Ethosuximide was not associated with any side effects in 9 patients with partial epilepsy ${ }^{43)}$, and it improved cognitive performance in individuals with and without epilepsy ${ }^{44)}$, suggesting that ethosuximide may be more beneficial than valproate for individuals with epilepsy. Although additional research is needed, ethosuximide may be the older drug with the best cognitive profile. 
Among the newer drugs, topiramate has been more consistently associated with detrimental influences on cognition than other AEDs. Patients treated with topiramate have demonstrated poorer verbal fluency, attention, and inhibitory performance than those treated with lamotrigine ${ }^{45)}$, and poorer verbal fluency and working memory than those treated with oxcarbazepine ${ }^{46)}$. Oxcarbazepine may be the better option, as it has been associated with only minor cognitive impairments ${ }^{477}$. Another study involving children with BCECTS showed no deterioration in cognitive performance, with some patients showing evidence of mild improvement ${ }^{48}$.

Based on current evidence, the agents least likely to interfere with cognitive processes are lamotrigine and levetiracetam. Lamotrigine treatment has shown positive effects on cognitive function in patients with epilepsy ${ }^{49}$ ), and levetiracetam has consistently been associated with widespread positive effects on cognition, suggesting that this agent may be particularly beneficial in patients with existing cognitive limitations ${ }^{38}$. Another study reported cognitive improvements in 10 of 32 children with atypical benign childhood epilepsy, with the remaining 22 showing no change ${ }^{50)}$.

Because the cognitive effects of AEDs can potentially be modified by discontinuing the drug, decreasing the dose, or switching to another medication, it is of critical importance to identify cognitive deficits that are potentiated by AED therapy. Identifying and minimizing the cognitive effects of AEDs is crucial in children because their developing nervous systems may be more vulnerable to the long-term consequences of AED-induced cognitive impairments ${ }^{38)}$.

In conclusion, epilepsy is a complex set of brain disorders, and epilepsy in childhood is often associated with reduced general intellectual functioning and specific cognitive impairments. The factors that can influence cognitive function in patients with epilepsy include genetics, ongoing seizures, different epilepsy syndromes, subclinical epileptiform discharges, psychosocial issues, underlying symptomatic causes of epilepsy, age at seizure onset, duration of epilepsy, and treatment with AEDs. An understanding of these deficits and associated factors will help each child maximize his or her academic potential, because research has shown that school achievement by children with epilepsy is often lower than would be predicted based on global measures of cognitive function.

\section{References}

1. MacAllister WS, Schaffer SG. Neuropsychological deficits in childhood epilepsy syndromes. Neuropsychol Rev 2007;17:427-44.

2. Bhise VV, Burack GD, Mandelbaum DE. Baseline cognition, behavior, and motor skills in children with new-onset, idiopathic epilepsy. Dev Med
Child Neurol 2010;52:22-6.

3. Bourgeois BF, Prensky AL, Palkes HS, Talent BK, Busch SG. Intelligence in epilepsy: a prospective study in children. Ann Neurol 1983;14:438-44.

4. Hommet C, Billard C, Motte J, Passage GD, Perrier D, Gillet P, et al. Cognitive function in adolescents and young adults in complete remission from benign childhood epilepsy with centro-temporal spikes. Epileptic Disord 2001;3:207-16.

5. Henkin Y, Sadeh M, Kivity S, Shabtai E, Kishon-Rabin L, Gadoth N. Cognitive function in idiopathic generalized epilepsy of childhood. Dev Med Child Neurol 2005;47:126-32.

6. Pinton F, Ducot B, Motte J, Arbues AS, Barondiot C, Barthez MA, et al. Cognitive functions in children with benign childhood epilepsy with centrotemporal spikes (BECTS). Epileptic Disord 2006;8:11-23.

7. Danielsson J, Petermann F. Cognitive deficits in children with benign rolandic epilepsy of childhood or rolandic discharges: a study of children between 4 and 7 years of age with and without seizures compared with healthy controls. Epilepsy Behav 2009;16:646-51.

8. Pascalicchio TF, de Araujo Filho GM, da Silva Noffs MH, Lin K, Caboclo LO, Vidal-Dourado M, et al. Neuropsychological profile of patients with juvenile myoclonic epilepsy: a controlled study of 50 patients. Epilepsy Behav 2007;10:263-7.

9. Farwell JR, Dodrill CB, Batzel LW. Neuropsychological abilities of children with epilepsy. Epilepsia 1985;26:395-400.

10. Bailet LL, Turk WR. The impact of childhood epilepsy on neurocognitive and behavioral performance: a prospective longitudinal study. Epilepsia 2000;41:426-31.

11. Mirsky AF, Primac DW, Marsan CA, Rosvold HE, Stevens JR. A comparison of the psychological test performance of atients with focal and nonfocal epilepsy. Exp Neurol 1960;2:75-89.

12. Jambaque I, Dellatolas G, Dulac O, Ponsot G, Signoret JL. Verbal and visual memory impairment in children with epilepsy. Neuropsychologia 1993;31:1321-37.

13. Aldenkamp AP, Arends J. Effects of epileptiform EEG discharges on cognitive function: is the concept of "transient cognitive impairment" still valid? Epilepsy Behav 2004;5 Suppl 1:S25-34.

14. Sonmez F, Atakli D, Sari H, Atay T, Arpaci B. Cognitive function in juvenile myoclonic epilepsy. Epilepsy Behav 2004;5:329-36.

15. Devinsky O, Gershengorn J, Brown E, Perrine K, Vazquez B, Luciano D. Frontal functions in juvenile myoclonic epilepsy. Neuropsychiatry Neuropsychol Behav Neurol 1997;10:243-6.

16. Iqbal N, Caswell HL, Hare DJ, Pilkington O, Mercer S, Duncan S. Neuropsychological profiles of patients with juvenile myoclonic epilepsy and their siblings: a preliminary controlled experimental video-EEG case series. Epilepsy Behav 2009;14:516-21.

17. Pulsipher DT, Seidenberg M, Guidotti L, Tuchscherer VN, Morton J, Sheth RD, et al. Thalamofrontal circuitry and executive dysfunction in recent-onset juvenile myoclonic epilepsy. Epilepsia 2009;50:1210-9.

18. Pavone P, Bianchini R, Trifiletti RR, Incorpora G, Pavone A, Parano E. Neuropsychological assessment in children with absence epilepsy. Neurology 2001;56:1047-51.

19. Weglage J, Demsky A, Pietsch M, Kurlemann G. Neuropsychological, intellectual, and behavioral findings in patients with centrotemporal spikes with and without seizures. Dev Med Child Neurol 1997;39:64651.

20. Staden U, Isaacs E, Boyd SG, Brandl U, Neville BG. Language dys- 
function in children with Rolandic epilepsy. Neuropediatrics 1998;29: 242-8.

21. Yung AW, Park YD, Cohen MJ, Garrison TN. Cognitive and behavioral problems in children with centrotemporal spikes. Pediatr Neurol 2000; 23:391-5.

22. Baglietto MG, Battaglia FM, Nobili L, Tortorelli S, De Negri E, Calevo MG, et al. Neuropsychological disorders related to interictal epileptic discharges during sleep in benign epilepsy of childhood with centrotemporal or Rolandic spikes. Dev Med Child Neurol 2001;43:40712.

23. Günduz E, Demirbilek V, Korkmaz B. Benign rolandic epilepsy: neuropsychological findings. Seizure 1999;8:246-9.

24. Bulgheroni S, Franceschetti S, Vago C, Usilla A, Pantaleoni C, D'Arrigo $S$, et al. Verbal dichotic listening performance and its relationship with EEG features in benign childhood epilepsy with centrotemporal spikes. Epilepsy Res 2008;79:31-8.

25. Northcott E, Connolly AM, Berroya A, Sabaz M, McIntyre J, Christie $\mathrm{J}$, et al. The neuropsychological and language profile of children with benign rolandic epilepsy. Epilepsia 2005;46:924-30.

26. Deonna T, Zesiger P, DavidoffV, Maeder M, Mayor C, Roulet E. Benign partial epilepsy of childhood: a longitudinal neuropsychological and EEG study of cognitive function. Dev Med Child Neurol 2000;42:595-603.

27. Northcott E, Connolly AM, McIntyre J, Christie J, Berroya A, Taylor A, et al. Longitudinal assessment of neuropsychologic and language function in children with benign rolandic epilepsy. J Child Neurol 2006;21:51822 .

28. Holmes GL. Epilepsy in the developing brain: lessons from the laboratory and clinic. Epilepsia 1997;38:12-30.

29. Metz-Lutz MN, Kleitz C, de Saint Martin A, Massa R, Hirsch E, Marescaux C. Cognitive development in benign focal epilepsies of childhood. Dev Neurosci 1999;21:182-90.

30. D'Alessandro P, Piccirilli M, Tiacci C, Ibba A, Maiotti M, Sciarma T, et al. Neuropsychological features of benign partial epilepsy in children. Ital J Neurol Sci 1990;11:265-9.

31. Chilosi AM, Brovedani P, Moscatelli M, Bonanni P, Guerrini R. Neuropsychological findings in idiopathic occipital lobe epilepsies. Epilepsia 2006;47 Suppl 2:76-8.

32. Germano E, Gagliano A, Magazu A, Sferro C, Calarese T, Mannarino E, et al. Benign childhood epilepsy with occipital paroxysms: neuropsychological findings. Epilepsy Res 2005;64:137-50.

33. Gulgonen S, Demirbilek V, Korkmaz B, Dervent A, Townes BD. Neuropsychological functions in idiopathic occipital lobe epilepsy. Epilepsia 2000;41:405-11.

34. Jeong MH, Yum MS, Ko TS, You SJ, Lee EH, Yoo HK. Neuropsychological status of children with newly diagnosed idiopathic childhood epilepsy. Brain Dev 2011;33:666-71.

35. Hermann B, Jones J, Sheth R, Dow C, Koehn M, Seidenberg M.
Children with new-onset epilepsy: neuropsychological status and brain structure. Brain 2006;129(Pt 10):2609-19.

36. Farwell JR, Lee YJ, Hirtz DG, Sulzbacher SI, Ellenberg JH, Nelson KB. Phenobarbital for febrile seizures: effects on intelligence and on seizure recurrence. N Engl J Med 1990;322:364-9.

37. Tonekaboni SH, Beyraghi N, Tahbaz HS, Bahreynian SA, Aghamohammadpoor M. Neurocognitive effects of phenobarbital discontinuation in epileptic children. Epilepsy Behav 2006;8:145-8.

38. Eddy CM, Rickards HE, Cavanna AE. The cognitive impact of antiepileptic drugs. Ther Adv Neurol Disord 2011;4:385-407.

39. Wesnes KA, Edgar C, Dean AD, Wroe SJ. The cognitive and psychomotor effects of remacemide and carbamazepine in newly diagnosed epilepsy. Epilepsy Behav 2009;14:522-8.

40. Sun W, Wang Y, Wang W, Wu X. Attention changes in epilepsy patients following 3-month topiramate or valproate treatment revealed by eventrelated potential. Int J Psychophysiol 2008;68:235-41.

41. Donati F, Gobbi G, Campistol J, Rapatz G, Daehler M, Sturm Y, et al. The cognitive effects of oxcarbazepine versus carbamazepine or valproate in newly diagnosed children with partial seizures. Seizure 2007;16:670-9.

42. Stores G, Williams PL, Styles E, Zaiwalla Z. Psychological effects of sodium valproate and carbamazepine in epilepsy. Arch Dis Child 1992; 67:1330-7.

43. Capovilla G, Beccaria F, Veggiotti P, Rubboli G, Meletti S, Tassinari CA. Ethosuximide is effective in the treatment of epileptic negative myoclonus in childhood partial epilepsy. J Child Neurol 1999;14:395-400.

44. Browne TR, Dreifuss FE, Dyken PR, Goode DJ, Penry JK, Porter RJ, et al. Ethosuximide in the treatment of absence (peptit mal) seizures. Neurology 1975;25:515-24.

45. Blum D, Meador K, Biton V, Fakhoury T, Shneker B, Chung S, et al. Cognitive effects of lamotrigine compared with topiramate in patients with epilepsy. Neurology 2006;67:400-6.

46. Kim SY, Lee HW, Jung DK, Suh CK, Park SP. Cognitive effects of lowdose topiramate compared with oxcarbazepine in epilepsy patients. J Clin Neurol 2006;2:126-33.

47. Aikia M, Kalviainen R, Sivenius J, Halonen T, Riekkinen PJ. Cognitive effects of oxcarbazepine and phenytoin monotherapy in newly diagnosed epilepsy: one year follow-up. Epilepsy Res 1992;11:199-203.

48. Tzitiridou M, Panou T, Ramantani G, Kambas A, Spyroglou K, Panteliadis C. Oxcarbazepine monotherapy in benign childhood epilepsy with centrotemporal spikes: a clinical and cognitive evaluation. Epilepsy Behav 2005;7:458-67.

49. Pressler RM, Binnie CD, Coleshill SG, Chorley GA, Robinson RO. Effect of lamotrigine on cognition in children with epilepsy. Neurology 2006;66:1495-9.

50. von Stulpnagel C, Kluger G, Leiz S, Holthausen H. Levetiracetam as addon therapy in different subgroups of "benign" idiopathic focal epilepsies in childhood. Epilepsy Behav 2010;17:193-8. 